\title{
Safe(r) transesophageal echocardiography and COVID-19
}

\author{
David Bracco, MD
}

Received: 7 April 2020/Revised: 8 April 2020/Accepted: 8 April 2020/Published online: 20 April 2020

(C) Canadian Anesthesiologists' Society 2020

\section{To the Editor,}

The coronavirus disease 2019 (COVID-19) has spread around the world and changed everyday anesthesia practice. COVID-19 is associated with myocardial injury in a significant proportion of patients. ${ }^{1}$ Transesophageal echocardiography (TEE) is a valuable bedside tool and may be useful in the cardiovascular assessment of some COVID-19 patients. Nevertheless, repeated advancing and withdrawing of the TEE probe through the aerodigestive tract during a typical TEE examination makes it an aerosolgenerating medical procedure. ${ }^{2,3}$ It also risks droplet and contact contamination.

Herein, we present a simple method to limit contamination of the operating room during a perioperative TEE examination using a standard laparoscopy camera sleeve (EZSert ${ }^{\circ}$ Drape Video Camera, 18x244 cm; Microtek Medical Inc, Columbus, OH, USA) (Figure A). Prior to insertion, the laparoscopy camera sleeve is mounted on the TEE probe to cover the handle. The bite block/mouthpiece is secured to the stretchable distal end of the camera sleeve, which is reinforced with the tapes incorporated into the sleeve itself. While wearing appropriate personal protective equipment, the echocardiographer places the bite block/mouthpiece into the patient's mouth and the TEE examination is performed by manipulating the probe through the sleeve (Figure B). After the examination is completed, the TEE probe is removed from the patient and completely withdrawn in the laparoscopy sleeve. The mouthpiece is then carefully withdrawn from the patient and "invaginated" into the sleeve.

This simple technique, using widely available operating room supplies, allows a "cleaner" TEE examination in COVID-19 (or other similarly infected) patients. This reduces oropharyngeal secretions from the patient's mouth being potentially aerosolized or otherwise spread via contact or droplet means while manipulating the TEEprobe.
D. Bracco, MD ( $\square)$

Critical Care and Trauma Montréal General Hospital, McGill

University Health Center, Montreal, QC, Canada

e-mail: david.Bracco@McGill.Ca 
Figure The use of a standard laparoscopic camera sleeve drape to reduce contamination during transesophageal echocardiography (TEE) examination. A) The TEE probe is inserted into the sleeve drape and the bite block/mouthpiece is secured to the stretchable end of the drape and secured with the sleeve's tapes. B) During the TEE examination, the probe is advanced and withdrawn as needed through the sleeve drape
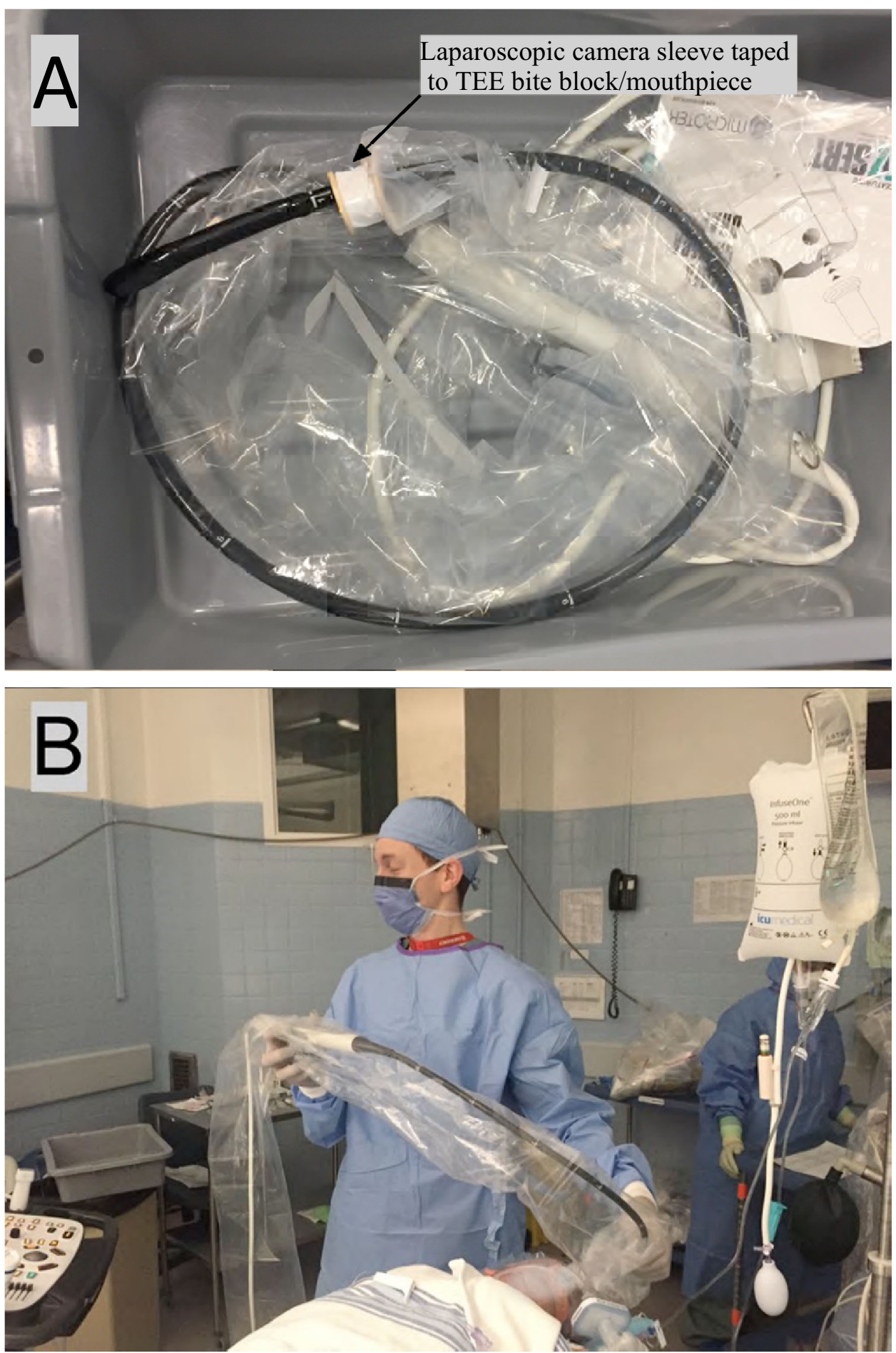

Conflicts of interest None.

\section{Funding statement None.}

Editorial responsibility This submission was handled by Dr. Hilary P. Grocott, Editor-in-Chief, Canadian Journal of Anesthesia.

\section{References}

1. Huang C, Wang $Y$, Li X, et al. Clinical features of patients infected with 2019 novel coronavirus in Wuhan. China. Lancet 2020; 395: 497-506.

2. American College of Cardiology. CVD in the Setting of COVID19: Considerations to Prepare Patients, Providers, Health Systems 
2020. Available from URL: https://www.acc.org/latest-incardiology/articles/2020/03/19/13/14/cvd-in-the-setting-of-covid19-coronavirus-considerations-to-prepare-patients-providershealth-systems (accessed April 2020).

3. American Society of Echocardiography. Coronavirus (COVID-19) Resources. ASE Statement on Protection of Patients and Echocardiography Service Providers During the COVID-19
Outbreak. Available from URL: https://www.asecho.org/covid19-resources/ (accessed April 2020).

Publisher's Note Springer Nature remains neutral with regard to jurisdictional claims in published maps and institutional affiliations. 